\title{
Evaluation of the relationship between the IL-17A gene expression level and regulatory miRNA-9 in relation to tumor progression in patients with non-small cell lung cancer: a pilot study
}

\author{
Monika Migdalska-Sęk ${ }^{1}$ (]) Katarzyna Góralska ${ }^{1} \cdot$ Sławomir Jabłoński ${ }^{2} \cdot$ Jacek Kordiak $^{2} \cdot$ Ewa Nawrot $^{1}$. \\ Justyna M. Kiszałkiewicz ${ }^{1}$ - Dorota Pastuszak-Lewandoska ${ }^{3} \cdot$ Kamila Baran $^{1}$ - Michał Stuss ${ }^{4}$. \\ Ewa Brzeziańska-Lasota ${ }^{1}$
}

Received: 26 June 2019 / Accepted: 24 October 2019 / Published online: 9 November 2019

(c) The Author(s) 2019

\begin{abstract}
A pro-inflammatory cytokine, IL-17A, is associated with increased risk of developing numerous cancers, including nonsmall cell lung cancer (NSCLC). IL-17A is a target gene for miR-9. This encouraged us to analyze these two genes in terms of their usefulness as prognostic markers in NSCLC. The expression levels of $I L-17 A$ gene and miR-9 was assessed in 26 NSCLC tissue samples and 26 unchanged lung tissue adjacent to lung tumors (control tissue), using qPCR. In both tissue groups, a decreased expression of $I L-17 A$ was observed in $100 \%$ of samples. Increased expression of miRNA-9 was observed in $92 \%$ of tumor samples, and in $100 \%$ of control samples. Neither statistical differences in the level of expression $I L-17 \mathrm{~A}$ depending on the patient's age, gender, smoking status, nor histopathology of the cancer was found. Regarding the presence of nodule metastasis ('N' value in TNM classification), significantly lower expression level of $I L-17 A$ was observed in cN2 as compared with $\mathrm{cN} 1$ group. Additionally, statistically lower $I L-17 \mathrm{~A}$ expression was found in III versus II tumor stage (cAJCC classification). Significant negative correlation between both studied genes was revealed in SCC subgroup. This leads to the conclusion that miRNA-9 can regulate the expression of $I L-17 A$ as an IL-17A mRNA antagonistic mediator. Inhibition of proinflammatory action of $I L-17 A$ in correlation with tumor progression can be related to various activity of Th17 cells on cancer development according to its immunogenicity, and also may suggest suppressive role of $I L-17 A$ in tumor progression. However, because of low number of analyzed samples, further studies on the functional role of $I L-17 \mathrm{~A}$ in development and/ or progression NSCLC seem warranted.
\end{abstract}

Keywords Interleukin-17A $\cdot$ miRNA-9 $\cdot$ Non-small cell lung cancer $\cdot$ Expression level

Monika Migdalska-Sęk

monika.migdalska-sek@umed.lodz.pl

1 Department of Biomedicine and Genetics, Medical University of Lodz, Poland St. 251, C-5, 92-213 Lodz, Poland

2 Clinic of Thoracic Surgery, General and Oncological Surgery University Clinical Hospital named after the Military Medical Academy - Central Veterans' Hospital, Medical University of Lodz, Poland St. Żeromskiego 113, 90-549 Lodz, Poland

3 Department of Microbiology and Laboratory Medical Immunology, Medical University of Lodz, Poland St. Pomorska 251, C-5, 92-213 Lodz, Poland

4 Department of Endocrine Disorders and Bone Metabolism, Medical University of Lodz, Poland St. Żeligowskiego 7/9, 90-752 Lodz, Poland

\section{Introduction}

Lung cancer is considered the second most common cancer in the world and the most common cause of death in oncology patients. According to the prognosis of the Ministry of Health, the prevalence of lung cancer is gradually increasing. It is estimated that in 2029 the number of new cases in Poland may exceed 32,000. The most common (as much as $85 \%$ of cases) form of lung cancer is non-small cell carcinoma (NSCLC), which includes squamous cell carcinoma (SCC), adenocarcinoma (AC) and large cell carcinoma (LCC) [1].

Standard diagnosis is based on X-ray and computed tomography imaging. Currently, more and more research concern the application of molecular techniques in the diagnosis of NSCLC, including searching for genetic 
markers in material collected from patients during tissue biopsy (lungs) and the so-called liquid biopsy (plasma, sputum, blood). Molecular factors are used to assess the prognosis and determine the probability of effective therapy. The most popular markers include BRCA1, ERCCl, $R R M 1$ and EGFR genes [1,2].

It was observed that the development of cancer in the lungs is associated with long-term smoking by the patient and the accompanying process of chronic inflammation of the lung [2]. Numerous lymphocytes capable of secretion of many chemokines and chemotactic cytokines enter the tumor microenvironment, stimulating and sustaining the process. Continuous cytokine secretion can stimulate the growth of cancer cells, suppress their apoptosis, promote tissue invasion, and metastasis. Numerous tumor cells have receptors for chemokines and proinflammatory cytokines on the surface of the cell membrane. One of them is the CCL20/CCR6 receptor pair, which plays an important role in the immunization of the lung in the course of, among others, chronic obstructive pulmonary disease or interstitial pulmonary fibrosis, and is associated with NSCLC progression [3]. CCL20/CCR6 is a pair of receptors for IL-17A, which is a precursor for the proinflammatory IL-17 cytokine family. Within the microenvironment of the tumor $I L-17 A$ can be secreted by Th17 lymphocytes, CD8 T-lymphocytes, $\gamma \delta \mathrm{T}$ and NK cells. The interaction of IL-17 with its receptor on the surface of fibroblasts or tumor cells stimulates the secretion of other pro-inflammatory cytokines, e.g. IL-6 and metalloproteases. Studies conducted in patients with lung cancer demonstrated that increased secretion of IL-6 is associated with poor prognosis of cancer. It is also suggested that changes in $I L$ $17 \mathrm{~A}$ expression levels may also be related to the advancement of NSCLC. Investigations on various cancers (such as colon, breast) reported association of $I L-17 \mathrm{~A}$ with the proliferation of cancer cells, but these mechanism is not yet fully understood $[4,5]$.

Particular interest of scientists is currently associated with a class of regulatory microRNAs (miRNAs). These are short non-coding RNA chains that affect the expression of many genes $[6,7]$. Numerous studies have confirmed their potential as diagnostic and/or prognostic markers of many types of cancer, including lung cancer. It is suggested that miR-9-3p may regulate expression of $I L-17 \mathrm{~A}$, which is also associated with tumor growth. Hence, changes in the expression of miR-9-3p may indicate at the same time altered expression of the $I L-17 \mathrm{~A}$ gene, and so serve as a prognostic marker in the course of NSCLC $[8,9]$.

The aim of the study was to assess the levels of expression of $I L-17 A$ gene and miR-9 in patients with NSCLC in relation to the tumor characteristic (histopathological subtype, TNM and AJCC classification), and to determine whether correlation between gene $I L-17 A$ and miR-9 expression exists.

\section{Materials and methods}

\section{Clinical characterization of patients and the NSCLC tissue samples}

This study was conducted in accordance with Good Clinical Practice and the principles of the Helsinki Declaration. The protocols of this study were approved by the Bioethics Committee of the Medical University in Lodz (Resolution No. KE/745/18, 12 June 2018). All participants signed an individual consent form for participation in the study.

The study was conducted on a group of 26 (11 women and 15 men) adult patients with NSCLC, aged 51 to 81 years (mean age $66.96 \pm 7.95$ years). In patients, lung resection (pulmonectomy or lobectomy) was performed at the Department of Thoracic Surgery, General and Oncologic Surgery, Military Medical Academy Memorial Teaching Hospital of The Medical University of LodzCentral Veterans' Hospital, Lodz, Poland, between 2018 and 2019. For analysis, lung tissue samples (approximately $100 \mathrm{mg}$ ) were collected from primary lesion and operating margin ( $2 \mathrm{~cm}$ away from the primary lesion), as a control group (macroscopically unchanged lung tissue).

The resected primary tumors were post-operatively subjected to the histopathological analysis. NSCLC samples were classified as: squamous cell carcinoma (SCC) and adenocarcinoma (AC). The stage of cancer was established according to the TNM classification and the AJCC classification system [10]. The history of smoking was available for all patients: 25 of them were smokers or former smokers, and one patient never smoked. Patients were divided into groups depending on the members of packyears (PY, 1 Pack Year $=20$ cigarettes smoked per day for 1 year according to the NCI Dictionary of Cancer Terms) [11]. Patient demographic characteristics and features of lung cancer are shown in Table 1 .

\section{RNA isolation, qualitative and quantitative RNA assessment}

Lung tissue samples were placed in fixRNA buffer (Eurx, Gdańsk, Poland), then divided into smaller parts, homogenized and frozen at $-80{ }^{\circ} \mathrm{C}$ until use. Isolation of total RNA from tissue homogenates was performed using mirVana $^{\mathrm{TM}}$ miRNA Isolation Kit (Life Technologies, Carlsbad, CA) according to the manufacturer's protocol. Qualitative and quantitative evaluation of the isolated RNA was performed by spectrophotometric method, measuring the 
Table 1 Demographic characteristics of patients and features of lung cancer

\begin{tabular}{|c|c|c|c|}
\hline Patients' characteristics & \multicolumn{3}{|c|}{ Number of patients (\%) } \\
\hline \multicolumn{4}{|l|}{ Gender } \\
\hline Women & \multicolumn{3}{|l|}{$11(42)$} \\
\hline Men & \multicolumn{3}{|l|}{$15(58)$} \\
\hline \multicolumn{4}{|l|}{ Age (years) } \\
\hline$\leq 65$ & \multicolumn{3}{|l|}{$12(46)$} \\
\hline$>65$ & \multicolumn{3}{|l|}{$14(54)$} \\
\hline \multicolumn{4}{|l|}{ Smoking history } \\
\hline$\leq 40 \mathrm{PYs}$ & \multicolumn{3}{|l|}{$13(52)$} \\
\hline$>40 \mathrm{PYs}$ & \multicolumn{3}{|l|}{$12(48)$} \\
\hline Former smokers & \multicolumn{3}{|l|}{$11(44)$} \\
\hline Current smokers & \multicolumn{3}{|l|}{$14(56)$} \\
\hline \multicolumn{2}{|l|}{ Tumors' characteristics } & \multicolumn{2}{|l|}{ Number of cases (\%) } \\
\hline \multicolumn{4}{|l|}{ Histopathological subtype } \\
\hline \multicolumn{2}{|l|}{$\mathrm{SCC}$} & \multicolumn{2}{|l|}{$14(54)$} \\
\hline \multicolumn{2}{|l|}{$\mathrm{AC}$} & \multicolumn{2}{|l|}{$12(46)$} \\
\hline \multicolumn{2}{|l|}{ TNM classification } & cTNM & pTNM \\
\hline \multicolumn{4}{|l|}{ Tumor size $(\mathrm{T})$} \\
\hline \multicolumn{2}{|l|}{$\mathrm{T} 1$} & $6(23)$ & $7(27)$ \\
\hline \multicolumn{2}{|l|}{$\mathrm{T} 2$} & $16(62)$ & $15(58)$ \\
\hline \multicolumn{2}{|l|}{$\mathrm{T} 3$} & $4(15)$ & $4(15)$ \\
\hline \multicolumn{4}{|l|}{ Presence of metastasis $(\mathrm{N})$} \\
\hline \multicolumn{2}{|l|}{ No } & $7(27)$ & $15(58)$ \\
\hline \multicolumn{2}{|l|}{ N1 } & $16(61.5)$ & $9(35)$ \\
\hline \multicolumn{2}{|l|}{$\mathrm{N} 2$} & $3(11.5)$ & $2(7)$ \\
\hline \multicolumn{2}{|l|}{ AJCC staging } & cAJCC & pAJCC \\
\hline \multicolumn{2}{|l|}{ I } & $7(27)$ & $11(42)$ \\
\hline \multicolumn{2}{|l|}{ II } & $14(54)$ & $11(42)$ \\
\hline \multicolumn{2}{|l|}{ III } & $5(19)$ & $4(15)$ \\
\hline
\end{tabular}

$p$ pathological, $c$ clinical

absorbance with the Eppendorf BioPhotometerTM Plus (Eppendorf, Hamburg, Germany), at 260/280 nm wavelengths. Them RNA was aliquoted and frozen at $-80{ }^{\circ} \mathrm{C}$ until the real-time polymerase chain reaction (qPCR) was performed.

\section{Evaluation of gene/miRNA expression}

The reverse transcription (RT) reaction for gene was performed using the High-Capacity cDNA Reverse Transcription Kit (Applied Biosystems, USA), in a volume of $20 \mu \mathrm{L}$. The reaction mixture contained: $10 \times \mathrm{RT}$ buffer, $25 \times \mathrm{dNTP}$ Mix $(100 \mathrm{mM}), 10 \times$ RT Random Primers, MultiScribe ${ }^{\mathrm{TM}}$ Reverse Transcriptase $(50 \mathrm{U} / \mu \mathrm{L})$, RNase Inhibitor and nuclease-free water. $100 \mathrm{ng}$ of total RNA was added to the reaction mixture. The negative control was carried out using water instead of RNA. The following conditions were used:
10 min at $25{ }^{\circ} \mathrm{C}, 120 \mathrm{~min}$ at $37^{\circ} \mathrm{C}, 5 \mathrm{~min}$ at $85^{\circ} \mathrm{C}$ and cooling at $4{ }^{\circ} \mathrm{C}$.

The reverse transcription (RT) for miRNA was carried out using of $5 \mu \mathrm{L}(10 \mathrm{ng})$ of total RNA and TaqMan ${ }^{\circledR}$ MicroRNA Reverse Transcription Kit (Applied Biosystems, Carlsbad, CA) in a volume of $15 \mu \mathrm{L}$. RT master mix contained: $25 \times$ dNTP Mix $(100 \mathrm{mM})$, MultiScribe ${ }^{\mathrm{TM}}$ Reverse Transcriptase $(50 \mathrm{U} / \mu \mathrm{L}), 10 \times \mathrm{RT}$ buffer, RNase Inhibitor (20 U/ $\mu \mathrm{L})$, nuclease-free water and specific RT primers (small RNA-specific RT primers) included in individual TaqMan ${ }^{\circledR}$ MicroRNA Assays: hsa-miR-9 (AUAAAGCUA GAUAACCGAAAGU) and RNU6B (CGCAAGGATGAC ACGCAAATTCGTGAAGCGTTCCATATTTTT) as endogenous control (Applied Biosystems, Carlsbad, CA). RT reaction was performed in a Personal Thermocycler (Eppendorf, Germany) in the following conditions: $30 \mathrm{~min}$ at $16^{\circ} \mathrm{C}$, followed by $30 \mathrm{~min}$ at $42{ }^{\circ} \mathrm{C}$, then the samples were heated to 
$85{ }^{\circ} \mathrm{C}$ for $5 \mathrm{~min}$, and held at $4{ }^{\circ} \mathrm{C}$. RT products were stored at $-20{ }^{\circ} \mathrm{C}$ until further analysis.

Relative gene/miRNA expression was assessed by realtime polymerase chain reaction (qPCR) using 7900HT Fast Real-Time PCR System apparatus (Applied Biosystems, Carlsbad, CA). Total reaction mixture volume of $20 \mu \mathrm{L}$ contained: cDNA (1-100 ng), KAPA PROBE FAST qPCR Master Mix (2X) ABI Prism ${ }^{\mathrm{TM}}$ (Kapa Biosystems Ltd, London, UK), RNase-free water and 20xTaqMan® Gene Expression Assay for the following genes: IL17A (Hs00174383_m1), and $A C T B$ (Hs99999903_m1) selected as the reference gene in the qPCR reaction. The following assays for miRNAs were selected: hsa-miR-9-3p, and RNU6B as the endogenous control. The relative expression level of the tested gene/miRNA was evaluated by delta-delta CT method (TaqMan Relative Quantification Assay software, Applied Biosystems) and presented as RQ value relative to the $A C T B / R N U 6 B$ reference gene/miRNA, respectively. The following formula was used to determine the $\Delta \Delta \mathrm{CT}$ value: $\Delta \Delta \mathrm{CT}=\Delta \mathrm{CT}$ test sample $-\Delta \mathrm{CT}$ calibrator sample. For calibrator (commercial sample-Total RNA, Invitrogen ${ }^{\mathrm{TM}}$, USA), RQ value was considered equal to 1 . The obtained results were compared in terms of the NSCLC histopathological subtype, cancer stage (TNM, AJCC), age of patients, gender and smoking history. In the case of the test samples, the increased expression was recognized when the RQ value was more than 1 and the decreased expression-when the RQ value was less than 1 .

\section{Statistical analysis}

In order to check the occurrence of statistical significance between the analyzed groups, Mann-Whitney U-test and/ or the Kruskal-Wallis test was used depending on the size of the groups. The Spearman rank correlation coefficient was used to measure the direction and strength of the association for individual variables. The statistical analysis was carried out using Statistica 13.1 program (StatSoft, Cracow, Poland). For all statistical analysis, the level of statistical significance was assumed at $\mathrm{p}<0.05$. The results are presented as medians.

\section{Results}

\section{IL17A gene expression analysis}

The relative expression level of $I L-17 A$ was analyzed in both lung cancer tissue (NSCLC) and in control tissue (macroscopically unchanged lung tissues adjacent to lung tumors). In both groups, for all samples (100\%) a decreased level of expression of the tested gene was observed $(\mathrm{RQ}<1)$ in relation to the calibrator (see Fig. 1a).

Median RQ values of $I L-17 A$ gene in NSCLC group versus control group were the following: 0.032 versus 0.068 ; respectively. Statistical analysis didn't confirm significant differences in the expression level of the tested gene in NSCLC versus control tissue $(\mathrm{p}=0.191$, Mann-Whitney U-test).

Mann-Whitney U-test showed no significant correlation between RQ values of $I L-17 A$ and the demographic features of NSCLC patients, patients' age (two age groups: $\leq 65$ years and $>65$ years: 0.029 vs. $0.033 ; p=0.489$ ), gender (women vs. men: 0.033 vs. $0.032 ; \mathrm{p}=0.350$ ), smoking habit (current smokers vs. former smokers: 0.029 vs. $0.033 ; p=0.366)$, and history of smoking evaluated as PY ( $\leq 40$ PYs vs. $>40$ PYs: 0.033 vs. $0.031 ; \mathrm{p}=0.341)$. In addition, an analysis was carried out in the entire group of smokers to see if there is a correlation between the expression of $I L-17 A$ and the amount of cigarettes smoked in relation to the length of the smoking (PYs). Spearman's rank correlation revealed rho $=-0.120$, with no statistical significant $(\mathrm{p}=0.338)$.

The relative expression level of $I L-17 A$ was analyzed depending on the histopathological features of tumor. The results are presented in Table 2.

Regarding $I L-17 A$ expression among the NSCLC histopathological subtypes: SCC vs. AC, the difference was not statistically significant ( $\mathrm{p}>0.05$, Mann-Whitney U-test). The expression level of $I L-17 A$ correlated with the stage of cancer according to TNM and AJCC was analyzed according to the pathological (p) and clinical (c) evaluation using TNM and AJCC classifications. The RQ value decreased with tumor size in both pT and cT groups: pT1 versus pT2 versus pT3 and cT1 versus cT2 versus cT3, however the differences were not significant $(\mathrm{p}>0.05$, Kruskal-Wallis test). According to the presence of metastasis to the nodules (pTNM staging, 'N' value), it was observed that RQ value of $I L-17 A$ was highest in patient with $\mathrm{pN} 1$, lower in pN0 and lowest in pN2, but without statistical significance ( $p>0.05$, Kruskal-Wallis test). Analysis of RQ values in $\mathrm{cN}$ groups demonstrated higher RQ in $\mathrm{cN} 1$ than in $\mathrm{cN} 0$ or cN2 ( $p=0.033$, Kruskal-Wallis test). Significant differences were observed between $\mathrm{cN} 1$ versus $\mathrm{cN} 2$ group $(\mathrm{p}=0.022$, Mann-Whitney U-test). The results are shown in Fig. 2.

In the pathological evaluation of tumor stages (pAJCC classification), the median RQ value was lower in stage III, and higher in I and II stages, but without statistical significance ( $\mathrm{p}>0.05$, Kruskal-Wallis test). According to the cAJCC classification, we observed the highest RQ value in group II, lower in I and the lowest in III ( $p=0.043$, Kruskal-Wallis test). Significant differences were demonstrated between II and III tumor stages $(p=0.006$, Mann-Whitney U-test). The results are presented in Fig. 3. 


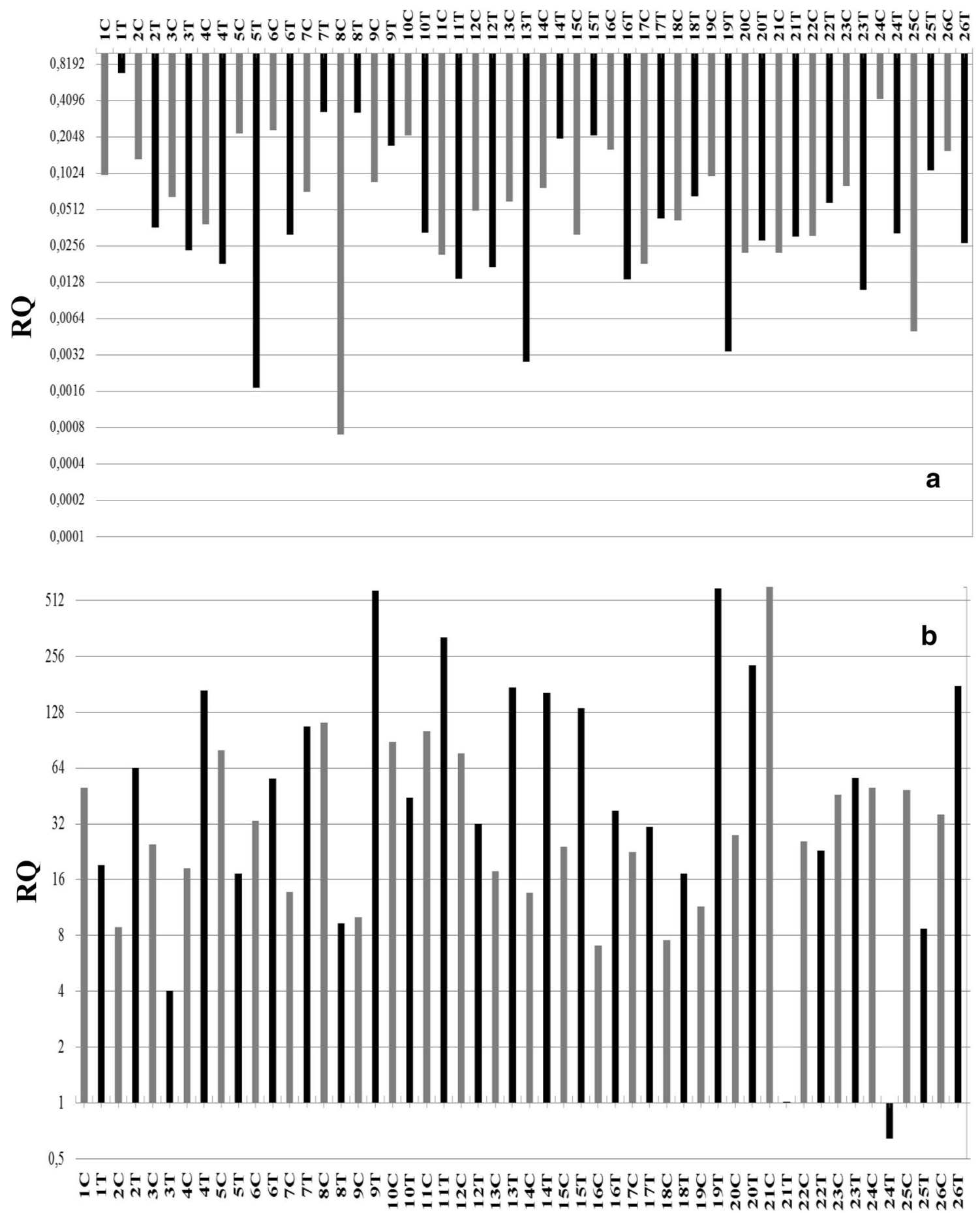

Fig. 1 The results of qPCRs presented as $\log 10$ (RQ) of all studied samples, for $I L-17 A$ (a), and miR-9 (b); $C$ control tissue, $T$ tumor tissue

\section{miRNA-9 expression analysis}

The relative expression level of miRNA-9 was analyzed both in lung cancer tissue (NSCLC) and in control tissue (macroscopically unchanged lung tissues adjacent to lung tumors). In NCSLC group, decreased miRNA-9 expression
$(\mathrm{RQ}<1)$ was observed in $1 / 26(4 \%)$ of the tested samples, in $1 / 26(4 \%)$ the expression profile was unchanged $(\mathrm{RQ}=1)$, whereas in 24/26 (92\%) of samples the expression was increased (RQ $>1)$. In the control tissue, in all samples $(100 \%)$ the increased expression level of analyzed miRNA was observed (RQ $>1$ ) (see Fig. 1b). Median RQ values 
Table 2 Median RQ values of $I L-17 A$ gene and miR-9 versus histopathological features of tumor
Fig. 2 Box-and-whisker plots representing $I L-17 A$ expression levels (median RQ values) in the studied groups according to the ' $\mathrm{N}$ ' value (cTNM staging)

\begin{tabular}{|c|c|c|c|c|c|c|}
\hline & \multicolumn{2}{|l|}{$I L-17 A$} & \multicolumn{2}{|l|}{$\operatorname{miR}-9$} & \multicolumn{2}{|c|}{$\begin{array}{l}\text { Correlation } I L-17 A \\
\text { versus mir-9 } \\
\text { p-value }\end{array}$} \\
\hline \multicolumn{7}{|c|}{ Histopathological subtype } \\
\hline SCC & 0.033 & & 50.409 & & $0.034^{*}$ & \\
\hline $\mathrm{AC}$ & $\begin{array}{l}0.031 \\
p=0.817\end{array}$ & & $\begin{array}{l}46.977 \\
p=0.939\end{array}$ & & 0.633 & \\
\hline \multicolumn{7}{|c|}{ Tumor size $(\mathrm{T})$} \\
\hline $\mathrm{T} 1$ & 0.043 & 0.036 & 37.744 & 82.359 & 0.939 & 0.623 \\
\hline $\mathrm{T} 2$ & 0.033 & 0.035 & 56.210 & 41.088 & 0.451 & 0.787 \\
\hline $\mathrm{T} 3$ & $\begin{array}{l}0.024 \\
p=0.776\end{array}$ & $\begin{array}{l}0.022 \\
p=0.344\end{array}$ & $\begin{array}{l}32.558 \\
p=0.650\end{array}$ & $\begin{array}{l}111.547 \\
p=0.791\end{array}$ & 0.400 & 0.800 \\
\hline \multicolumn{7}{|c|}{ Presence of metastasis $(\mathrm{N})$} \\
\hline N0 & 0.032 & 0.024 & 56.210 & 37.744 & 0.940 & 0.702 \\
\hline N1 & 0.043 & 0.040 & 30.750 & 54.196 & 0.576 & 0.322 \\
\hline $\mathrm{N} 2$ & $\begin{array}{l}0.022 \\
p=0.622\end{array}$ & $\begin{array}{l}0.014 \\
p=0.033^{*}\end{array}$ & $\begin{array}{l}161.231 \\
p=0.858\end{array}$ & $\begin{array}{l}56.385 \\
p=0.744\end{array}$ & - & 0.667 \\
\hline \multicolumn{7}{|c|}{ AJCC staging } \\
\hline I & 0.033 & 0.024 & 63.960 & 37.744 & 0.450 & 0.645 \\
\hline II & 0.033 & 0.040 & 31.957 & 37.591 & 0.180 & 0.637 \\
\hline III & $\begin{array}{l}0.022 \\
p=0.651\end{array}$ & $\begin{array}{l}0.017 \\
p=0.043 *\end{array}$ & $\begin{array}{l}32.558 \\
p=0.698\end{array}$ & $\begin{array}{l}166.710 \\
p=0.259\end{array}$ & 0.400 & 0.747 \\
\hline
\end{tabular}

*Statistically significant $\mathrm{p}<0.05$

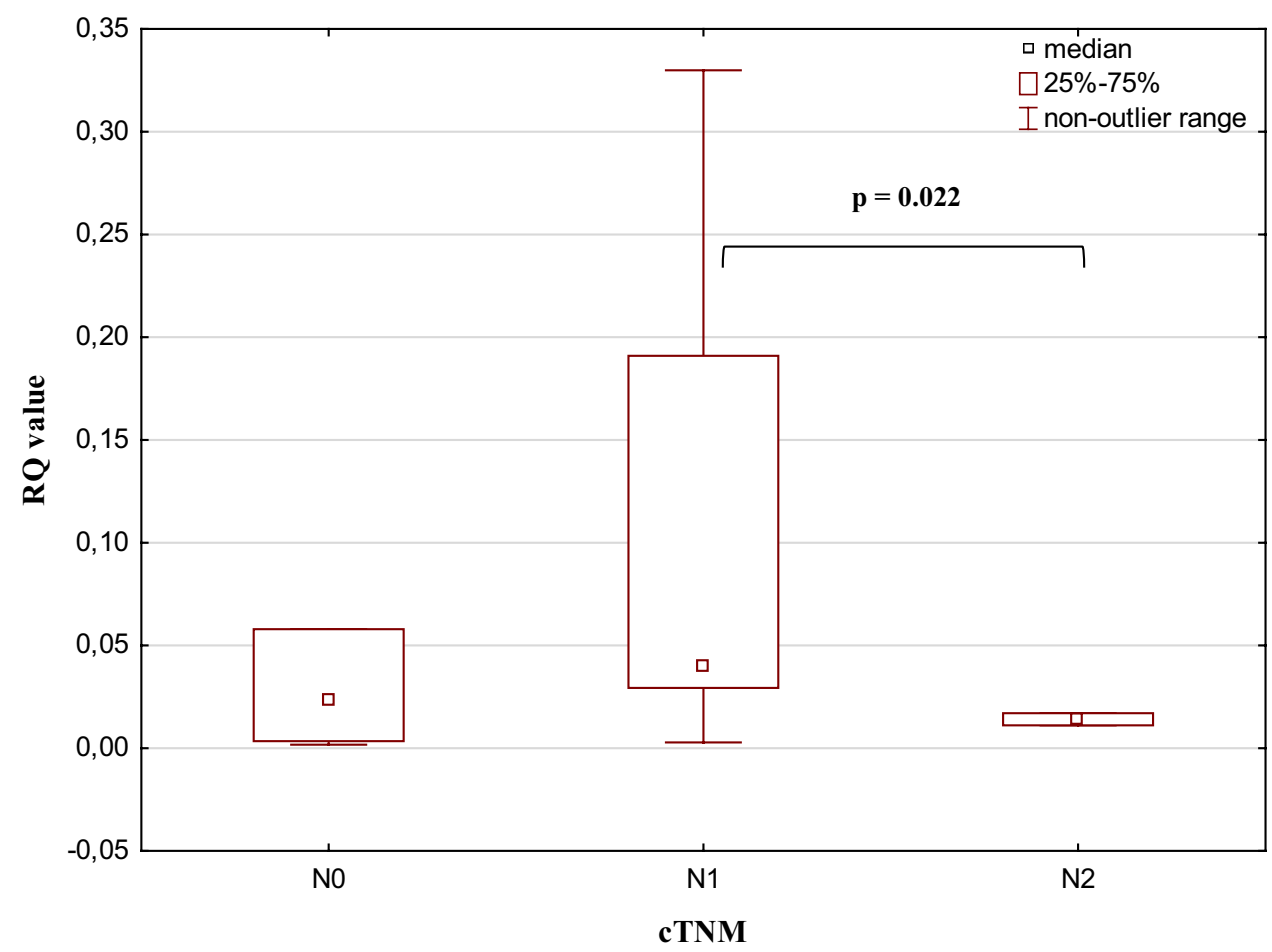

of miRNA-9 in patients versus control group were: 50.321 versus 26.697; respectively. Statistical analysis didn't reveal significant differences $(p=0.210$, Mann-Whitney U-test).
Mann-Whitney U-test showed no significant correlation between RQ values of miRNA-9 and the demographic features of NSCLC patients, patients' age (two 
Fig. 3 Box-and-whisker plots representing $I L-17 A$ expression levels (median RQ values) in the studied groups according to cAJCC classification

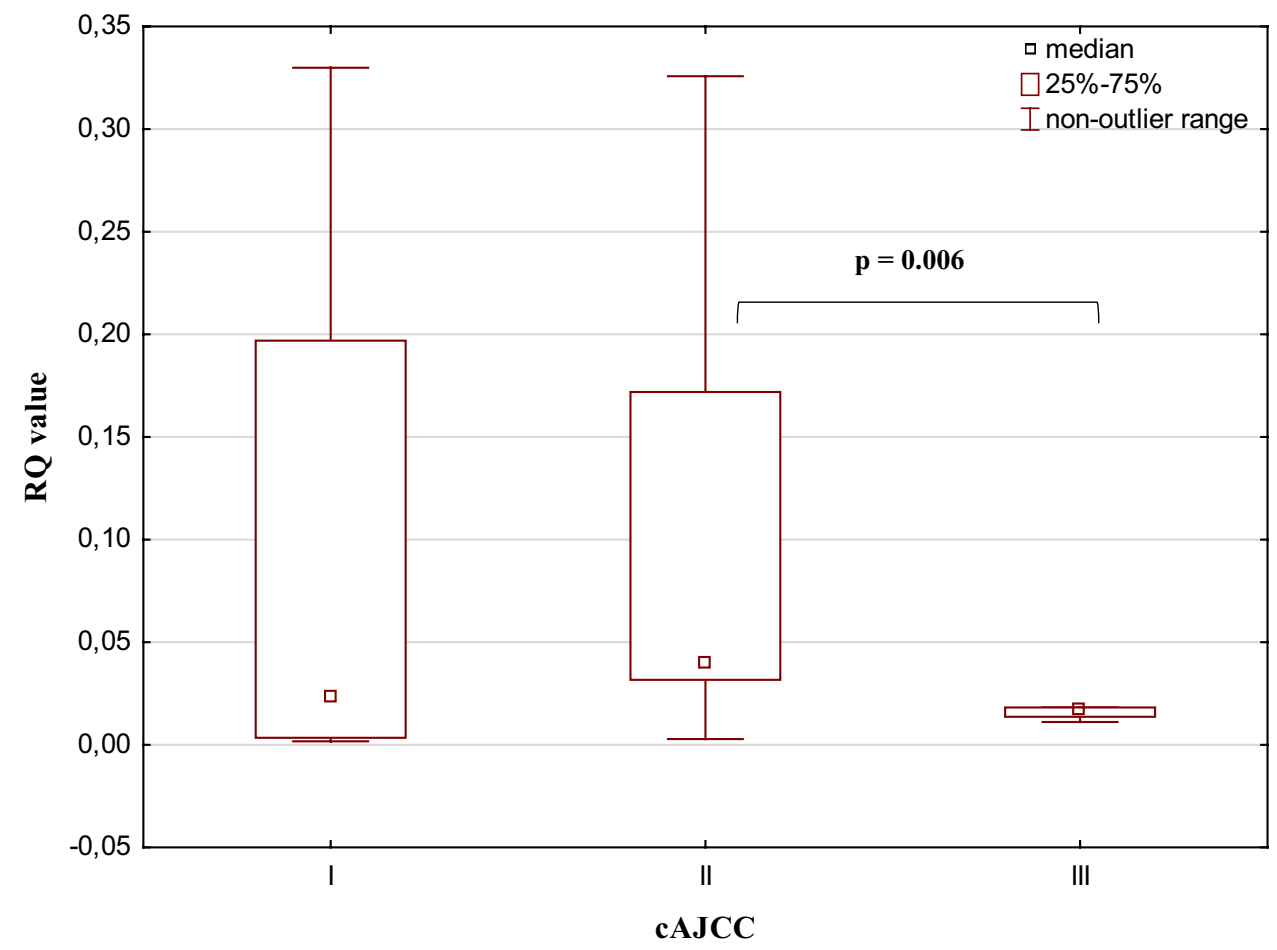

age groups: $\leq 65$ years and $>65$ years: 56.298 vs. 41.088 ; $\mathrm{p}=0.625$ ), gender (women vs. men: 37.744 vs. 56.210, $\mathrm{p}=0.467$ ), smoking habit (current smokers $v$ s former smokers: 41.088 vs. $63.960, p=0.891$ ), and history of smoking evaluated as PY ( $\leq 40$ PYs vs. $>40$ PYs: 133.967 vs. 27.444; $\mathrm{p}=0.135$ ). In addition, an analysis was carried out in the whole group of smokers to see if there is a correlation between the expression of miRNA-9 and the amount of cigarettes smoked in relation to the length of the smoking (PYs). Spearman's rank correlation revealed rho $=-0.139$, with no statistical significance $(\mathrm{p}=0.507)$.

The expression of miRNA-9 was analyzed in relation to the histopathological features of tumor (see Table 2). Regarding miRNA-9 expression in NSCLC histopathological subtypes: SCC vs AC, the difference was not statistically significant ( $p>0.05$, Mann-Whitney U-test). The level of miRNA-9 expression was analyzed in accordance with the pathological (p) and clinical (c) evaluation (TNM and AJCC classification). Median RQ values in groups according to pTNM staging were similar in pT1 and pT3, and higher in pT2, with no statistical significance ( $p>0.05$, Kruskal-Wallis test). In the clinical evaluation of tumor size, the highest RQ was observed in cT3 group, lower in cT1 and the lowest in cT2, without statistical significance ( $\mathrm{p}>0.05$, Kruskal-Wallis test). According to the presence of nodule metastasis (pTNM staging, ' $N$ ' value), it was observed that RQ value was the highest in patient with $\mathrm{pN} 2$, lower in $\mathrm{pN} 0$ and the lowest in $\mathrm{pN} 1$, but without statistical significance ( $\mathrm{p}>0.05$, Kruskal-Wallis test). Analysis of RQ values in groups according to the $\mathrm{cN}$ classifications showed an increase in the level of miRNA-9 expression along with lymph node involvement: N0 versus N1 versus N2, but without statistical significance ( $\mathrm{p}>0.05$, Kruskal-Wallis test). In pAJCC groups, the median RQ value were similar in stage II and III, and higher in I stage, but without statistical significance ( $p>0.05$, Kruskal-Wallis test). Regarding cAJCC classification, we observed the highest RQ value in group III, lower in I and in II ( $\mathrm{p}>0.05$, Kruskal-Wallis test).

\section{Correlation between the expression level of IL-17A gene and miRNA-9}

There were differences between expression of analyzed parameters in NSCLC and control samples. The levels of expression of $I L-17 A$ of NSCLC versus control samples were 0.032 versus 0.068 , and for miRNA-9 were 50.321 versus 26.697 .

The simultaneous decreased expression level of $I L-17 A$ and increased expression level of miRNA-9 were observed in 25 NSCLC samples (96\%). Significant negative correlation was found between $I L-17 A$ and miR-9 expression levels in SCC subgroup $(\mathrm{p}=0.034$, rho $=-0.569$, Spearman's rank correlation coefficient; power of the test is 0.543 , t-test) (see Table 2). There were no other statistically significant correlations between the expression of studied $I L-17 A$ and miR-9 and analyzed parameters, such as patients' age and gender, smoking history and tumor staging according to TNM and AJCC classifications ( $\mathrm{p}>0.05$, Spearman's rank correlation). 


\section{Discussion}

IL-17A is a pro-inflammatory cytokine produced predominantly by Th17 CD4+helper cells. At the same time, it is expressed also by CD8+ lymphocytes, neutrophils, eosinophils, macrophages and monocytes [5, 12]. The direct relationship between $I L-17 \mathrm{~A}$ and the increased risk of developing of numerous cancers, including NSCLC, has been demonstrated. On this basis it is considered as the central regulator of lung tumor growth [13]. Among other things, it promotes the migration and invasion of lung cancer cells via the NF-KB/ZEB1 signaling pathway. Gu et al. [14] have tracked this pathway in human lung cancer cell line A549 exposed to the IL-17A. Increased levels of IL-17A stimulated ephitelial to mesenhymal transition of cells, promoting cancer development [14]. At the same time, IL-17A is involved in the tumor cell angiogenesis. Increased IL17A expression correlates with increased levels of tumor microvessel density and vascular endothelial growth factor. Research conducted by Pan et al. [15] suggested stimulation of angiogenesis factors via STAT3/GIV signaling pathway. In addition, direct and indirect involvement of IL-17A in proliferation, apoptosis and immunomodulation of tumor cells as well as promotion of metastasis was found [5]. The animal model has also demonstrated the involvement of IL17A in the formation of inflammation, which contributes to resistance to PD-1 blockade and sensitizes tumors to neutrophil depletion [16].

Numerous studies indicate the usefulness of the evaluation of IL-17A expression as a NSCLC diagnostic marker. The majority of research uses immunochemical methods, our research is one of the first which evaluate $I L-17 A$ expression levels with qPCR method. Li et al. [4] observed a significantly increased level of IL-17A in cancer patients $(38 \mathrm{pg} / \mathrm{ml})$ compared to healthy subjects (29 pg/ml). Research of Pan et al. [17] also showed a higher level of IL-17A in patients with NSCLC $(21 \mathrm{pg} / \mathrm{ml})$ than in control patients $(11 \mathrm{pg} / \mathrm{ml})$. The aim of our study was to determine the level of $I L-17 \mathrm{~A}$ gene expression in patients at various stages of NSCLC. The control material was macroscopically unchanged lung tissue surrounding the primary tumor obtained from the same patient. No differences were observed between $I L-17 \mathrm{~A}$ expression from tumor and control material. Similarly, the lack of statistical significance between the test and control tissue was observed by Kwiecień et al. [18]. As demonstrated by immunohistochemistry, increased expression usually refers to cancer cells, but sometimes it can occur in non-cancerous tissue, hence there may be no statistical differences in our own studies [19].

Smoking is considered as one of the risk factors for NSCLC developing. According to literature, smoking may also correlate with elevated levels of $I L-17 A$ [19]. In our study such correlation wasn't found, similar results were also obtained by Pan et al. [17].

Both our study and studies conducted by other authors have not shown any correlation between the level of $I L-17 \mathrm{~A}$ expression and the patient's age and gender, and the histological type of cancer [17, 19, 20].

However, a statistically significant relationship was found with the presence of metastasis according to the TNM classification. Significantly, higher levels of $I L-17 A$ expression were found in $\mathrm{cN} 1$ compared to $\mathrm{cN} 2$ group. Xu et al. [20] noted higher interleukin expression in the case of both lymph node and distant metastasis. Other researchers have also found higher $I L-17 \mathrm{~A}$ expression in patients with more advanced cancer-III and IV stage according to TNM classification than in patients with I and II tumor stage $[17,19$, 20]. However, our results showed a difference in the level of $I L-17 A$ expression between II and III AJCC stages.

The available data from literature suggest the usefulness of $I L-17 A$ as not only diagnostic but also prognostic marker. The meta-analysis performed on the basis of research conducted among the Chinese population showed a correlation of the analyzed interleukin with the histological type of tumor and tumor progression according to TNM classification, as well as with overall survival of lung cancer patients [21], which also confirms the results of our research.

In recent years, particular attention has been paid to the miRNAs, which perform regulatory functions against numerous genes and participate in the activity of signaling pathways. The relationship of increased expression of miRNAs and numerous diseases, especially cancers, has been documented in many studies. Researchers suggest the possibility of using miRNAs as non-invasive diagnostic markers. In the case of lung cancer, miR-9 is considered a prognostic biomarker [8]. It is involved in the regulation and migration of cancer cells, and promotes cell growth and metastasis $[9,22,23]$. On the other hand, it was found that NSCLC cells overexpressing miR-9 may exhibit increased sensitivity to cisplatin, which is used in cancer chemotherapy [24]. It partly overlaps the study of gastric cancer, which showed that overexpression of miR-9-3p inhibits the development of this type of cancer [25].

Our results didn't show any relation between the level of miR-9-3p expression, age and sex, smoking status of the patient, as well as the type of histological cancer and the stage of development according to the TNM and AJCC classification. However, other authors found the correlation between increased miR-9 level and the development of cancer. Xu et al. [8] revealed such a correlation with TNM grade, tumor size and presence of lymph node metastasis. $\mathrm{Li}$ et al. [22] observed a relationship between expression of miR-9-5p and the presence of metastasis, a significantly higher expression was observed in $\mathrm{N} 1$ and $\mathrm{N} 2$ patients according to TNM classification. In studies performed on 
cell lines, the authors found stimulation of tumor cell proliferation and migration in the presence of the overexpression of miR-9-5p [22]. They also found worse prognosis in patients with a higher level of expression of miR-9-5p.

The contribution of miR-9 to the development of NSCLC and its usefulness as a diagnostic and prognostic marker are still under discussion. The molecular targets for miR-9 are still unknown. Due to the similarity of miR-9-3p sequences to the 7mer-A1 region in IL17A $3^{\prime} U T R$, the contribution of miR-9-3p in the regulation of $I L-17 A$ expression is suggested in TargetScanHuman 7.2. database [26]. Literature data suggested $I L-17$ and miR-9 are involved in the regulation of epithelial-mesenchymal transition -like transformation affecting the level of the same factors. IL-17 reduces the expression of E-cadherin and increases the level of vimentin protein [14]. In contrast, miR-9 increases the expression of E-cadherin, and decreased the level of vimentin [9]. In our study, we found a negative correlation between the expression of $I L-17 A$ and miR-9-3p, but only in patients with squamous cell carcinoma. The reduced level of $I L-17 A$ expression and the overexpression of miR-9-3p in lung cancer tissue may be associated with the miR-9 function as a negative IL-17A regulator. The lack of literature data indicates the need for further research in this area.

In conclusion, the observed significantly reduced level of $I L-17 A$ expression in a small group of patients with distant metastases (N2) and AJCC stage III suggests that the pro-inflammatory response of $I L-17 A$ is inhibited along with tumor progression, and indicate the suppressive role of $I L-17 A$ in NSCLC development. Due to the fact that the number of cases in the groups N0/N1 and AJCC I/II was sufficient for correct statistical analysis and the level of IL17A expression increased with the progression of cancer (although didn't reach statistical significance), we do not exclude the oncogenic activity of IL17A in the course of NSCLC, more so that the literature data is controversial [14, 15, 27]. Probably, IL-17 as a pleiotropic cytokine can have a suppressive or stimulating effect on tumor growth. It has been shown that IL-17 can promote the growth of cancer cells through pro-inflammatory and proangiogenic activities $[15,27,28]$. At the same time, many data support the anti-cancer effect of Th17 lymphocytes. It seems, therefore, that Th17 cells may have various effects on the development of cancer depending on its immunogenicity, clinical advancement (different role in the early and late stages), as well as the origin of cancer and the role of inflammatory processes and angiogenesis in its pathogenesis [27]. Nevertheless, the correlation between miRNA- 9 overexpression and low expression of $I L-17 A$ in SCC allows to conclude that miRNA-9 can regulate the expression of $I L-17 A$ as an IL-17A mRNA antagonistic mediator and the mechanism of this regulation may be important in development of SCC.
Author contributions Monika Migdalska-Sęk and Katarzyna Góralska have contributed equally to this work.

Funding This study was supported by the Medical University of Lodz (Statute No. 503/1-013-02/503-11-003). The founder had no role in study design data collection and analysis, decision to publish or preparation of the manuscript.

\section{Compliance with ethical standards}

Conflict of interest All authors declare that they have no conflict of interest.

Open Access This article is distributed under the terms of the Creative Commons Attribution 4.0 International License (http://creativeco mmons.org/licenses/by/4.0/), which permits unrestricted use, distribution, and reproduction in any medium, provided you give appropriate credit to the original author(s) and the source, provide a link to the Creative Commons license, and indicate if changes were made.

\section{References}

1. Dylewska M, Mikułowska M, Nowak S, Falkiewicz B (2016) Rak płuca w Polsce_-perspektywa społeczna i medyczna 2016. Raport Sequence HC Partners Sp. z o.o. Instytut Zarządzania w Ochronie Zdrowia Uczelnia Łazarskiego, Warszawa [in Polish]

2. Potempa M, Jonczyk P, Zalewska-Ziob M (2014) Molekularne uwarunkowania raka płuca. Onkol Prak Klin 10(4):199-211 [in Polish]

3. Kirshberg S, Izhar U, Amir G, Dema J, Vernea F, Beider K, Shlomai Z, Wald H, Zamir G, Shapira OM, Peled A, Wald O (2011) Involvement of CCR3/CCL20/IL-17 axis in NSCLC disease progression. PLoS ONE 6(9):e24856. https://doi. org/10.1371/journal.pone.0024856

4. Li Q, Han Y, Fei G, Guo Z, Ren T, Liu Z (2012) IL-17 promoted metastasis of non-small-cell lung cancer cells. Immunol Lett 148:144-150. https://doi.org/10.1016/j.imlet.2012.10.011

5. Wu F, Xu J, Huang Q, Han J, Duan L, Fan J, Lv Z, Guo M, Hu G, Chen L, Zhang S, Tao X, Ma W, Jin Y (2016) The role of interleukin-17 in lung cancer. Med Inflam. https://doi. org/10.1155/2016/8494079

6. Choo K, Soon Y, Nguen P, Hiew M, Huang CJ (2014) MicroRNA-5p and $-3 p$ co-expression and cross-targeting in colon cancer cells. J Biomed Sci 21:95

7. Boeri M, Verri C, Conte D, Roz L, Modena P, Facchinetti F, Calabro E, Croce CM, Pastorino U, Sozzi G (2011) MicroRNA signatures in tissues and plasma predict development and prognosis of computed tomography detected lung cancer. PNAS 108(9):3713-3718

8. Xu T, Liu X, Han L, Shen H, Liu L, Shu Y (2014) Up-regulation of miR-9 expression as a poor prognostic biomarker in patients with non-small cell lung cancer. Clin Transl Oncol 16(5):469475. https://doi.org/10.1007/s12094-013-1106-1

9. Xu G, Shao G, Pan Q, Sun L, Zheng D, Li M, Li N, Shi H, Ni Y (2017) MicroRNA-9 regulates non-small cell lung cancer cell invasion and migration by targeting eukaryotic translation initiation factor 5A2. Am J Trasl Res 9(2):478-488

10. American Joint Committee on Cancer Staging according to the IASLC Staging Project. 7th edition. Cancer 2010. http://cance rstaging.org/references-tools/quickreferences/documents/lungm edium.pdf. Accessed 30 Jan 2019 
11. NCI Dictionary of Cancer Terms. https://www.cancer.gov/publi cations/dictionaries/cancer-terms. Accessed 30 Jan 2019

12. Murugaiyan G, Saha B (2009) Protumor vs antitumor functions of IL-17. J Immunol 183(7):4169-4175. https://doi. org/10.4049/jimmunol.0901017

13. Reppert S, Koch S, Finotto S (2012) IL-17A is a central regulator of lung tumor growth. Oncoimmunology 1(5):783-785. https ://doi.org/10.4161/onci.19735

14. Gu K, Li M-M, Shen J, Liu F, Cao J-Y, Jin S, Yu Y (2015) Interleukin-17-induced EMT promotes lung cancer cell migration and invasion via NF- $\mathrm{KB} / \mathrm{ZEB} 1$ signal pathway. Am J Cancer Res 5(3):1169-1179

15. Pan B, Shen J, Cao J, Zhou Y, Shang L, Jin S, Cao S, Che D, Liu F, Yu Y (2015) Interleukin-17 promotes angiogenesis by stimulating VEGF production of cancer cells via the STAT3/ GIV signaling pathway in non-small-cell lung cancer. Sci Rep 5:16053. https://doi.org/10.1038/srep16053

16. Akbay EA, Koyama S, Liu Y, Dries R, Bufe LE, Silkes M, Alam MM, Magee DM, Jones R, Jinushi M, Kulkarni M, Carretero J, Wang X, Warner-Hatten T, Cavanaugh JD, Osa A, Kumanogoh A, Freeman GJ, Awad MM, Christiani DC, Bueno R, Hammerman PS, Dranoff G, Wong KK (2017) Interleukin-17A promotes lung tumor progression through neutrophil attraction to tumor sites and mediating resistance to PD-1 blockade. J Thorac Oncol 12(8):1268-1279. https://doi.org/10.1016/j.jtho.2017.04.017

17. Pan B, Che D, Cao J, Shen J, Jin S, Zhou Y, Liu F, Gu K, Man Y, Shang L, Yu Y (2015) Interleukin-17 levels correlate with poor prognosis and vascular endothelial growth factor concentration in the serum of patients with non-small cell lung cancer. Biomarkers 20(4):232-239. https://doi.org/10.3109/1354750X.2015.1068853

18. Kwiecien I, Stelmaszczyk-Emmel A, Polubiec-Kownacka M, Dziedzic D, Domagala-Kulawik J (2017) Elevated regulatory T cells, surface and intracellular CTLA-4 expression and interleukin-17 in the lung cancer microenvironment in humans. Cancer Immunol Immunother 66(2):161-170. https://doi.org/10.1007/ s00262-016-1930-6

19. Chen X, Wan J, Liu J, Xie W, Diao X, Xu J, Zhu B, Chen Z (2010) Increased IL-17-producing cells correlate with poor survival and lymphangiogenesis in NSCLC patients. Lung Cancer 69(3):348354. https://doi.org/10.1016/j.lungcan.2009.11.013
20. Xu C, Hao K, Yu L, Zhang X (2014) Serum interleukin-17 as a diagnostic and prognostic marker for non-small cell lung cancer. Biomarkers 19(4):287-290. https://doi.org/10.3109/13547 50X.2014.908954

21. Wang XF, Zhu YT, Wang JJ, Zeng DX, Mu CY, Chen YB, Lei W, Zhu YH, Huang JA (2017) The prognostic value of interleukin-17 in lung cancer: a systematic review with meta-analysis based on Chinese patients. PLoS ONE 12(9):e0185168. https:// doi.org/10.1371/journal.pone.0185168

22. Li G, Wu F, Yang H, Deng X, Yuan Y (2017) MiR-9-5p promotes cell growth and metastasis in non-small cell lung cancer through the repression of TGFBR2. Biomed Pharmacother 96:1170-1178. https://doi.org/10.1016/j.biopha.2017.11.105

23. Han L, Wang W, Ding W, Zhang L (2017) MiR-9 is involved in TGF- $\beta 1$-induced lung cancer cell invasion and adhesion by targeting SOX7. J Cell Mol Med 21(9):2000-2008. https://doi. org/10.1111/jcmm. 13120

24. Pan Q, Sun L, Zheng D, Li N, Shi H, Song J, Shao G (2018) MicroRNA-9 enhanced cisplatin sensitivity in nonsmall cell lung cancer cells by regulating eukaryotic translation initiation factor 5A2. Biomed Res Int. https://doi.org/10.1155/2018/1769040

25. Meng Q, Xiang L, Fu J, Chu X, Wang C, Yan B (2017) Transcriptome profiling reveals miR-9-3p as a novel tumor suppressor in gastric cancer. Oncotarget 8(23):37321-37331. https://doi. org/10.18632/oncotarget.16310

26. Agarwal V, Bell GW, Nam J-W, Bartel DP (2015) Predicting effective microRNA target sites in mammalian mRNAs. ELife 4:e05005. https://doi.org/10.7554/eLife.05005

27. Hus I, Maciąg E, Roliński J (2010) The role of Th17 cells in anticancer immunity. Postepy Hig Med Dosw 64:244-250 [in Polish]

28. Domagała-Kulawik J, Osińska I (2014) Immune alterations in lung cancer-the new therapeutic approach. Pneumonol Alergol Pol 82:286-299 [in Polish]

Publisher's Note Springer Nature remains neutral with regard to jurisdictional claims in published maps and institutional affiliations. 